\title{
KAJIAN TENTANG LAX PAIR DAN PENERAPANNYA PADA PERSAMAAN LIOUVILLE
}

\author{
ANDRENO JUANDA \\ Program Studi Matematika, \\ Fakultas Matematika dan Ilmu Pengetahuan Alam, Universitas Andalas, \\ Kampus UNAND Limau Manis Padang, Indonesia, \\ email : andreno.juanda11@gmail.com
}

\begin{abstract}
Abstrak. Lax pair merupakan pasangan dua operator diferensial yang jika disubstitusikan ke suatu persamaan (dinamakan persamaan Lax) akan menghasilkan suatu persamaan diferensial parsial tertentu. Jika suatu persamaan diferensial parsial memiliki Lax pair, maka hal itu mengindikasikan bahwa persamaan diferensial tersebut bersifat integrable. Dalam makalah ini akan dibahas analisis Lax pair secara umum, baik dalam bentuk operator $L$ dan $M$ maupun dalam bentuk matriks $X$ dan $T$. Selain itu juga dibahas penerapan Lax pair secara khusus pada persamaan Liouville dengan mengkonfirmasi sifat-sifat terkait.
\end{abstract}

Kata Kunci: Persamaan diferensial, Lax pair, Persamaan Liouville

\section{Pendahuluan}

Lax pair merupakan pasangan dua operator diferensial yang jika disubstitusikan ke suatu persamaan (dinamakan persamaan Lax) akan menghasilkan suatu persamaan diferensial parsial tertentu. Jika suatu persamaan diferensial parsial memiliki Lax pair, maka hal itu mengindikasikan bahwa persamaan diferensial tersebut bersifat integrable (dapat diselelesaikan secara eksak). Awal mula ide tentang Lax pair ini dipublikasikan oleh Peter Lax pada tahun 1968 [7]. Sejak saat itu Lax pair menjadi objek penting dalam analisis suatu sistem integrable. Suatu Lax pair terdiri dari operator $L$, yang bergantung terhadap $x, u_{x}, u_{x x}, \cdots$, dan operator $M$ yang bersamasama dengan operator $L$ merepresentasikan suatu persamaan diferensial parsial $F\left(x, t, u, u_{x}, u_{t}, \cdots\right)=0$ ketika disubstitusikan ke persamaan $L_{t}=[M, L]$ (disebut persamaan $L a x)$. Di sini notasi $[M, L]$ didefinisikan sebagai $[M, L]=(M L-L M)$ dan disebut sebagai komutator (commutator) dari operator $M$ dan $L$.

Proses menemukan $M$ dan $L$ yang bersesuaian dengan persamaan diferensial yang diberikan secara umum bersifat tak trivial. Oleh karena itu, jika ada petunjuk, maka membalikkan proses dengan terlebih dahulu menetapkan suatu $L$ dan $M$ dan kemudian menentukan persamaan diferensial parsial yang mana yang bersesuaian terkadang dapat memberikan hasil yang baik. Namun hal ini membutuhkan banyak percobaan (trial), dan tentu saja bisa tidak mengarah ke solusi yang dikehendaki. Karena eksistensi dari Lax pair mengindikasikan bahwa persamaan diferensial parsial yang bersesuaian bersifat integrable, maka menemukan Lax pair adalah suatu cara untuk menemukan persamaan diferensial parsial baru yang integrable [5]. 
Di samping itu, jika suatu Lax pair yang cocok dapat ditemukan untuk suatu persamaan diferensial parsial tertentu, maka hal itu memungkinkan Lax pair digunakan untuk menyelesaikan persamaan diferensial parsial tersebut dengan menggunakan suatu metode, seperti metode inverse scattering transform (IST) yang dikembangkan oleh Gardener, Greene, Kruskal, dan Miura [3].

Dalam makalah ini akan dijelaskan tentang konsep Lax pair secara umum dan dianalisis beberapa sifat terkait yang muncul, kemudian konsep tersebut akan diterapkan pada persamaan Liouville. Kajian tentang masalah ini mengeksplorasi kembali studi pada referensi [4] dan [5].

\section{Bentuk Operator}

Diberikan suatu operator linier $L$ yang bergantung pada fungsi $u(x, t)$, variabel spasial $x$ dan turunan spasial $u_{x}, u_{x x}, \cdots$, sedemikian sehingga

$$
L \psi=\lambda \psi, \psi=\psi(x, t),
$$

dimana $\lambda$ adalah nilai eigen dan $\psi$ adalah fungsi eigen yang bersesuaian dengan nilai eigen $\lambda$. Selanjutnya misalkan terdapat operator lain $M$, sedemikian sehingga berlaku

$$
\psi_{t}=M \psi
$$

Untuk menentukan syarat kompatibilitas bagi persamaan (2.1) dan (2.2), Ablowitz dan Clarkson [2] menurunkan persamaan (2.1) terhadap waktu $t$ dan kemudian gunakan aturan rantai, sehingga diperoleh

$$
L_{t} \psi+L \psi_{t}=\lambda_{t} \psi+\lambda \psi_{t} .
$$

Selanjutnya substitusikan persamaan (2.2) ke persamaan (2.3), maka didapatkan

$$
\begin{aligned}
L_{t} \psi+L M \psi & =\lambda_{t} \psi+\lambda M \psi \\
& =\lambda_{t} \psi+M \lambda \psi .
\end{aligned}
$$

Dengan menggunakan persamaan (2.1), maka persamaan (2.4) menjadi

$$
\begin{aligned}
L_{t} \psi+L M \psi & =\lambda_{t} \psi+M L \psi \\
\Leftrightarrow\left(L_{t}+L M-M L\right) \psi & =\lambda_{t} \psi .
\end{aligned}
$$

Dengan demikian, untuk memperoleh solusi non-trivial bagi fungsi eigen $\psi(x, t)$, haruslah

$$
L_{t}+[L, M]=0,
$$

dimana $[L, M]$ didefinisikan sebagai

$$
[L, M]=L M-M L
$$

yang akan bernilai benar jika dan hanya jika $\lambda_{t}=0$ atau dengan kata lain $\lambda$ tidak bergantung pada waktu.

Persamaan (2.6) memberikan syarat kompatibilitas bagi persamaan (2.1) dan (2.2) dan dikenal sebagai representasi Lax atau persamaan Lax dari suatu persamaan diferensial parsial yang diberikan. Selanjutnya $[L, M]$ pada persamaan $(2.7)$ 
merepresentasikan komutator dari dua operator $L$ dan $M$ yang membentuk suatu Lax pair.

Selanjutnya diberikan teorema tentang rumus koefisien polinomial dalam trace.

Teorema 2.1. [6] Misalkan polinomial karakteristik dari suatu matriks A yaitu

$$
P(\lambda)=\operatorname{det}(A-\lambda I)=b_{0} \lambda^{n}+b_{1} \lambda^{n-1}+b_{2} \lambda^{n-2}+\cdots+b_{n-1} \lambda+b_{n}
$$

dimana $A=\left(a_{i j}\right)$ adalah matriks berukuran $n \times n$ dan I adalah matriks identitas berukuran $n \times n$. Metode untuk menentukan $b_{i}$ pada (2.8) dilakukan secara rekursif sebagai berikut:

$$
\begin{aligned}
b_{0} & =(-1)^{n} \\
b_{1} & =-(-1)^{n} T_{1} \\
b_{2} & =-\frac{1}{2}\left[b_{1} T_{1}+(-1)^{n} T_{2}\right] \\
b_{3} & =-\frac{1}{3}\left[b_{2} T_{1}+b_{1} T_{2}+(-1)^{n} T_{3}\right] \\
\vdots & \\
b_{n} & =-\frac{1}{n}\left[b_{n-1} T_{1}+b_{n-2} T_{2}+\cdots+b_{1} T_{n-1}+(-1)^{n} T_{3}\right]
\end{aligned}
$$

dimana $T_{1}, T_{2}, \cdots, T_{n}$ berturut-turut merupakan trace dari matriks $A, A^{2}, \cdots, A^{n}$.

Pembuktian dari Teorema 2.1 dapat dilihat pada referensi [6].

\section{Bentuk Matriks}

Pada tahun 1974, Ablowitz, Kaup, Newell, dan Segur [1] mengembangkan suatu formulasi matriks untuk Lax pair untuk menghindari keharusan dalam menggunakan operator-operator Lax dengan orde yang lebih tinggi. Metode ini juga dikenal sebagai metode AKNS. Dalam analisisnya, mereka memperkenalkan sistem

$$
\begin{gathered}
D_{x} \Psi=X \Psi, \\
D_{t} \Psi=T \Psi,
\end{gathered}
$$

dimana matriks persegi $X$ dan $T$ berkorespondensi secara berturut-turut dengan operator $L$ dan $M$, dan $\Psi$ adalah suatu fungsi bernilai vektor. Matriks $X$ dan $T$ pada umumnya bergantung pada nilai eigen $\lambda$ yang bebas terhadap waktu dan ukuran dari $\Psi$ bergantung pada orde $L$. Dengan demikian, jika $L$ berorde 2 , maka vektor $\Psi$ mempunyai dua elemen, sedangkan $X$ dan $T$ masing-masing adalah matriks berukuran $2 \times 2$.

Dengan menggunakan persamaaan (2.7), (3.1) dan (3.2), diperoleh syarat kompatibilitas bagi persamaan (3.1) dan (3.2), yaitu dengan menghitung

$$
\begin{aligned}
{\left[D_{t}, D_{x}\right] \Psi } & =\left(D_{t} D_{x}-D_{x} D_{t}\right) \Psi \\
& =D_{t} D_{x} \Psi-D_{x} D_{t} \Psi \\
& =D_{t}(X \Psi)-D_{x}(T \Psi) \\
& =\left(D_{t} X\right) \Psi+X\left(D_{t} \Psi\right)-\left(D_{x} T\right) \Psi-T\left(D_{x} \Psi\right)=\mathbf{0} .
\end{aligned}
$$


Persamaan (3.3) dapat ditulis ulang menjadi

$$
\begin{array}{r}
\left(D_{t} X\right) \Psi+X T \Psi-\left(D_{x} T\right) \Psi-T X \Psi=\mathbf{0} \\
\Longleftrightarrow\left(D_{t} X\right) \Psi-\left(D_{x} T\right) \Psi+X T \Psi-T X \Psi=\mathbf{0} \\
\Longleftrightarrow\left(D_{t} X-D_{x} T+[X, T]\right) \Psi=\mathbf{0} .
\end{array}
$$

Untuk memperoleh solusi non-trivial bagi fungsi $\psi$, maka haruslah

$$
D_{t} X-D_{x} T+[X, T]=\mathbf{0},
$$

yang memberikan syarat kompatiblitas bagi persamaan (3.1) dan (3.2) dan dikenal sebagai persamaan matriks Lax. Dalam hal ini,

$$
[X, T]=X T-T X
$$

didefinisikan sebagai komutator matriks.

Jika $X$ bebas terhadap $t$, maka persamaan (3.4) menjadi

$$
D_{x} T=[X, T],
$$

yang memberikan representasi Lax bagi suatu persamaan stasioner. Pasangan matriks $(X, T)$ disebut matriks Lax pair untuk suatu persamaan stasioner.

Berikut beberapa sifat yang berlaku pada representasi Lax (3.7).

Sifat 3.1. [4] Misalkan $(X, T)$ adalah matriks Lax pair untuk suatu persamaan stasioner, maka $\operatorname{Tr}\left(T^{k}\right)$ adalah konstan terhadap $x, \forall k \in \mathbb{N}$.

Bukti. Akan ditunjukkan bahwa turunan $\operatorname{Tr}\left(T^{k}\right)$ terhadap $x$ bernilai nol untuk setiap $k \in \mathbb{N}$. Perhatikan bahwa

$$
\begin{aligned}
\frac{d \operatorname{Tr}\left(T^{k}\right)}{d x} & =\operatorname{Tr} \frac{d T^{k}}{d x} \\
& =\operatorname{Tr}\left(T_{x} T^{k-1}+T T_{x} T^{k-2}+\cdots+T^{k-1} T_{x}\right) \\
& =\operatorname{Tr}\left(T_{x} T^{k-1}\right)+\operatorname{Tr}\left(T T_{x} T^{k-2}\right)+\cdots+\operatorname{Tr}\left(T^{k-1} T_{x}\right) \\
& =\operatorname{Tr}\left(T_{x} T^{k-1}\right)+\operatorname{Tr}\left(T_{x} T^{k-2} T\right)+\cdots+\operatorname{Tr}\left(T_{x} T^{k-1}\right) \\
& =k \operatorname{Tr}\left(T_{x} T^{k-1}\right) \\
& =k \operatorname{Tr}\left((X T-T X) T^{k-1}\right) \\
& =k \operatorname{Tr}\left(X T^{k}-T X T^{k-1}\right) \\
& =k\left(\operatorname{Tr}\left(X T^{k}\right)-\operatorname{Tr}\left(X T^{k}\right)\right) \\
& =0 .
\end{aligned}
$$

Akibat yang menarik dari Sifat 3.1 adalah bahwa nilai eigen dari matriks $T$ juga konstan.

Akibat 3.2. [4] Misalkan (X,T) adalah matriks Lax pair untuk suatu persamaan stasioner, maka $\lambda$ adalah konstan terhadap $x$ untuk setiap $\lambda \in \operatorname{Spec}(T)$.

Bukti. Misalkan matriks $T$ berukuran $n \times n$. Berdasarkan Teorema 2.1, koefisienkoefisien dari polinomial karakteristik matriks $T$ dapat dinyatakan secara rekursif 
dalam $\operatorname{Tr}\left(T^{k}\right)$ dengan $k=1,2, \cdots, n$. Karena Sifat 3.1 menyatakan bahwa $\operatorname{Tr}\left(T^{k}\right)$ bernilai konstan, maka semua koefisien polinomial karakteristik juga bernilai konstan. Perhatikan bahwa setiap akar-akar polinomial dapat dinyatakan sebagai fungsi terhadap koefisien-koefisien polinomialnya. Karena nilai eigen matriks $T$ merupakan akar-akar polinomial karakteristik, dan semua koefisien polinomialnya bernilai konstan, maka nilai eigen matriks $T$ mestilah juga bernilai konstan.

Matriks Lax pair bagi suatu persamaan stasioner tidaklah unik. Sifat berikut mengkonfirmasi hal tersebut.

Sifat 3.3. [4] Misalkan (X,T) adalah matriks Lax pair untuk suatu persamaan stasioner, maka $\left(X, \gamma T^{k}\right)$ dengan $\gamma \in \mathbb{R}$ dan $k \in \mathbb{N}$ adalah matriks Lax pair yang lain untuk persamaan stasioner tersebut.

Bukti. Misalkan $(X, T)$ adalah matriks Lax pair untuk suatu persamaan stasioner. Untuk menunjukkan bahwa $\left(X, \gamma T^{k}\right)$ adalah juga matriks Lax pair untuk persamaan stasioner tersebut, maka pasangan matriks tersebut harus memenuhi persamaan matriks $\operatorname{Lax} D_{x}\left(\gamma T^{k}\right)=\left[X, \gamma T^{k}\right]$.

Perhatikan bahwa

$$
\begin{aligned}
D_{x}\left(\gamma T^{k}\right) & =\gamma D_{x}\left(T^{k}\right) \\
& =\gamma \sum_{i=0}^{k-1} T^{i} T_{x} T^{k-1-i} \\
& =\gamma \sum_{i=0}^{k-1} T^{i}[X, T] T^{k-1-i} \\
& =\gamma \sum_{i=0}^{k-1} T^{i}(X T-T X) T^{k-1-i} \\
& =\gamma\left(\sum_{i=0}^{k-1} T^{i} X T^{k-i}-\sum_{i=0}^{k-1} T^{i+1} X T^{k-i}\right) \\
& =\gamma\left(X T^{k}-T^{k} X\right) \\
& =\left[X, \gamma T^{k}\right] .
\end{aligned}
$$

\section{Lax pair untuk Persamaan Liouville}

Pada bab ini akan dibahas matriks Lax pair untuk persamaan Liouville [8]

$$
\frac{\partial^{2} u}{\partial t \partial x}-\exp (2 u)=0, u=u(x, t)
$$

dan mengkonfirmasi sifat-sifat terkait yang dibahas pada pembahasan sebelumnya. Persamaan Liouville sendiri diformulasikan oleh matematikawan Prancis, Joseph Liouville, dan muncul dalam kajian tentang koordinat isotermal pada geometri diferensial. 
Matriks Lax pair untuk persamaan ini diberikan dalam referensi [8], yaitu

$$
X=\left[\begin{array}{cc}
\frac{\partial u}{\partial x} & \lambda \\
\lambda & -\frac{\partial u}{\partial x}
\end{array}\right]
$$

dan

$$
T=\left[\begin{array}{cc}
0 & \frac{1}{\lambda} \exp (2 u) \\
0 & 0
\end{array}\right]
$$

Ini berarti bahwa jika $X$ dan $T$ pada persamaan (4.2) dan (4.3) disubstitusikan ke persamaan matriks Lax pair (3.4), maka akan diperoleh persamaan Liouville (4.1). Untuk menunjukkan hal ini, perhatikan bahwa

$$
D_{t} X=\frac{\partial}{\partial t}\left[\begin{array}{cc}
\frac{\partial u}{\partial x} & \lambda \\
\lambda & -\frac{\partial u}{\partial x}
\end{array}\right]=\left[\begin{array}{cc}
\frac{\partial^{2} u}{\partial t \partial x} & 0 \\
0 & -\frac{\partial^{2} u}{\partial t \partial x}
\end{array}\right]
$$

dan

$$
D_{x} T=\frac{\partial}{\partial x}\left[\begin{array}{cc}
0 & \frac{1}{\lambda} \exp (2 u) \\
0 & 0
\end{array}\right]=\left[\begin{array}{cc}
0 & \frac{2}{\lambda} \exp (2 u) \frac{\partial u}{\partial x} \\
0 & 0
\end{array}\right] .
$$

Selanjutnya perhatikan juga bahwa

$$
X T=\left[\begin{array}{ll}
0 & \frac{1}{\lambda} \exp (2 u) \frac{\partial u}{\partial x} \\
0 & \exp (2 u)
\end{array}\right]
$$

dan

$$
T X=\left[\begin{array}{cc}
\exp (2 u) & -\frac{1}{\lambda} \exp (2 u) \frac{\partial u}{\partial x} \\
0 & 0
\end{array}\right]
$$

sehingga diperoleh

$$
\begin{aligned}
{[X, T] } & =X T-T X \\
& =\left[\begin{array}{cc}
-\exp (2 u) & \frac{2}{\lambda} \exp (2 u) \\
0 & \exp (2 u)
\end{array}\right] .
\end{aligned}
$$

Dengan demikian dari persamaan (3.4) didapatkan

$$
\begin{aligned}
D_{t} X-D_{x} T+[X, T] & =\left[\begin{array}{cc}
\frac{\partial^{2} u}{\partial t \partial x}-\exp (2 u) & 0 \\
0 & -\frac{\partial^{2} u}{\partial t \partial x}+\exp (2 u)
\end{array}\right] \\
& =\left[\begin{array}{ll}
0 & 0 \\
0 & 0
\end{array}\right] .
\end{aligned}
$$

Jelas bahwa dari persamaan (4.6) diperoleh

$$
\frac{\partial^{2} u}{\partial t \partial x}-\exp (2 u)=0,
$$

yang merupakan persamaan Liouville (4.1).

Jika $u$ tidak bergantung waktu $t$, maka persamaan Liouville (4.1) menjadi

$$
\exp (2 u)=0
$$


yang memberikan persamaan stasioner bagi persamaan Liouville. Pasangan matriks $(X, T)$ merupakan matriks Lax pair untuk persamaan stasioner (4.7). Selanjutnya perhatikan bahwa

$$
\begin{aligned}
T^{2} & =\left[\begin{array}{ll}
0 & \frac{1}{\lambda} \exp (2 u) \\
0 & 0
\end{array}\right]^{2} \\
& =\left[\begin{array}{ll}
0 & \frac{1}{\lambda} \exp (2 u) \\
0 & 0
\end{array}\right]\left[\begin{array}{cc}
0 & \frac{1}{\lambda} \exp (2 u) \\
0 & 0
\end{array}\right] \\
& =\left[\begin{array}{ll}
0 & 0 \\
0 & 0
\end{array}\right] .
\end{aligned}
$$

Ini berarti

$$
T^{k}=\left[\begin{array}{ll}
0 & 0 \\
0 & 0
\end{array}\right],
$$

dengan $k \in \mathbb{N}$. Oleh karena itu $\operatorname{Tr}\left(T^{k}\right)=0$. Kenyataan ini mengkonfirmasi Sifat 3.1 bahwa $\operatorname{Tr}\left(T^{k}\right)$ adalah konstan.

Selanjutnya nilai eigen dari $T$ dapat dicari dengan menyelesaikan persamaan berikut:

$$
\begin{aligned}
\operatorname{det}(\lambda I-T) & =\operatorname{det}\left(\lambda\left[\begin{array}{ll}
1 & 0 \\
0 & 1
\end{array}\right]-\left[\begin{array}{cc}
0 & \frac{1}{\lambda} \exp (2 u) \\
0 & 0
\end{array}\right]\right) \\
& =\operatorname{det}\left(\left[\begin{array}{ll}
\lambda & 0 \\
0 & \lambda
\end{array}\right]-\left[\begin{array}{cc}
0 & \frac{1}{\lambda} \exp (2 u) \\
0 & 0
\end{array}\right]\right) \\
& =\operatorname{det}\left(\begin{array}{cc}
\lambda & \frac{1}{\lambda} \exp (2 u) \\
0 & \lambda
\end{array}\right) \\
& =\lambda^{2}=0 .
\end{aligned}
$$

Dari persamaan terakhir diperoleh nilai eigen dari matriks $T$, yaitu $\lambda_{1,2}=0$. Hal ini mengkonfirmasi Akibat 3.1 yang menyatakan bahwa setiap nilai eigen dari matriks $T$ bernilai konstan.

\section{Kesimpulan}

Dalam makalah ini telah dibahas analisis Lax pair secara umum, baik dalam bentuk operator $L$ dan $M$ maupun dalam bentuk matriks $X$ dan $T$. Beberapa sifat yang muncul dari Lax pair ini adalah:

1. Nilai $\operatorname{Tr}\left(T^{k}\right)$ selalu konstan untuk setiap $k \in \mathbb{N}$.

2. Setiap nilai eigen matriks $T$ bernilai konstan.

3. Jika $(X, T)$ merupakan suatu matriks Lax pair untuk suatu persamaan diferensial, maka $\left(X, \gamma T^{k}\right)$, dengan $\gamma \in \mathbb{R}$ dan $k \in \mathbb{N}$, juga merupakan Lax pair untuk persamaan diferensial tersebut (sifat ini menunjukkan bahwa Lax pair tidak unik).

Dalam makalah ini juga telah dibahas secara khusus penerapan Lax pair pada persamaan Liouville dan mengkonfirmasi sifat-sifat terkait. 
Sebagai saran untuk penelitian berikutnya, agar dilanjutkan pembahasan tentang Lax pair dalam menyelesaikan persamaan diferensial parsial dengan menggunakan metode inverse scattering transform.

\section{Ucapan Terimakasih}

Penulis mengucapkan terima kasih kepada Bapak Dr. Mahdhivan Syafwan, Bapak Dr. Admi Nazra, Bapak Bukti Ginting, M.Si, Bapak Narwen, M.Si dan Bapak Budi Rudianto, M.Si yang telah memberikan masukan dan saran sehingga makalah ini dapat diselesaikan dengan baik.

\section{Daftar Pustaka}

[1] Ablowitz, M. J., D. J. Kaup, A. C. Newell, and H. Segur. 1974. The inverse scattering transform - Fourier analysis for nonlinear problems. Stud. Appl. Math. 53: $249-315$.

[2] Ablowitz, M. J. and P. A. Clarkson. 1991. Solitons, Nonlinear Evolution Equations and Inverse Scattering (London Mathematical Society Lecture Note Series, 149). Cambridge: University Press.

[3] Gardener, C. S., J. Greene, M. Kruskal, and R. M. Miura. 1967. Method for solving the Korteweg-de Vries equation. Phys. Rev. Lett. 19, 1095 - 1097.

[4] Goriely, Alain. 2001. Integrability and Nonintegrability of Dynamical Systems. Singapura : World Scientific Publishing.

[5] Griffiths, Graham W. 2012. Lax Pairs. City University. UK. www.researchgate.net/publication/270581873_Lax_Pairs [diakses pada tanggal 22 Februari 2016].

[6] L. A. Zadeh and C. A. Desoer. 1963. Linier System Theory : The State Approach. New York: McGraw-HIll.

[7] Lax, P. 1968. Integrals of nonlinear equations of evolution and solitary waves, Comm. Pure Applied Math. 21: 467 - 490.

[8] Wu, P., X. Guan, Z. Xiong, and H. Zhou, 1992. A note on infinite conservation laws in Liouville equation. Chin. Phys. Lett. 9(7): 337 - 340. 